\title{
O Curso de Editoração da USP: Um Projeto Democrático
}

\author{
José de Paula Ramos Jr.* \\ Departamento de Jornalismo e Editoração da Escola de Comunicações e Artes da Universidade de São Paulo \\ * Autor para correspondência: jdepaula@usp.br
}

\section{RESUMO}

O presente relato procura apresentar de modo sucinto o processo de reformulação do Projeto Político-Pedagógico e as bases da nova estrutura curricular da graduação em Editoração da Escola de Comunicações e Artes da Universidade de São Paulo (ECA-USP). Tal reforma estendeu-se por mais de três anos e envolveu ampla participação de docentes, alunos e ex-alunos. Em linhas gerais, por meio dessa iniciativa democrática, procurouse não só aperfeiçoar a qualidade acadêmica do curso, mas também permitir que ele contemplasse as mudanças significativas ocorridas na indústria do livro e no mercado editorial nos últimos anos, em virtude, sobretudo, da utilização em larga escala das novas tecnologias.

Palavras-chave: Curso de Editoração; Projeto Político-Pedagógico; Reforma Curricular.

\begin{abstract}
The present report seeks to present succinctly the process of reformulation of the political-pedagogical project and the bases of the new curricular structure of the graduation in Publishing of the School of Communications and Arts of the University of São Paulo (ECA-USP). This reform lasted more than three years and involved a wide participation of teachers, students and alumni. In general, through this democratic initiative, we seek not only to improve the academic quality of the course, but also to allow it to contemplate the significant changes that have occurred in the book industry and in the publishing market in recent years, mainly due to the large-scale use of the new technologies.
\end{abstract}

Keywords: Course of Publishing; Political-Pedagogical Project; Curricular Reform.

O curso superior de Editoração da Escola de Comunicações e Artes da Universidade de São Paulo (ECA-USP) foi o segundo criado no Brasil. Pertence ao Departamento de Jornalismo e Editoração (GJE), tem índice de evasão baixo e acolhe quinze ingressantes por ano, atendidos por um corpo docente que, atualmente, limita-se a catorze professores vinculados ao GJE.

De 1972, quando iniciou suas atividades, até 2014, formou 396 profissionais do livro. Dos egressos que seguem a carreira, alguns tornam-se bem-sucedidos empresários da indústria editorial, todos os demais encontram colocação no mercado de trabalho. O reconhecimento da alta qualidade do curso de Editoração da USP pode ser aferido, por exemplo, pelas cinco estrelas sempre atribuídas a ele pelo Guia do Estudante, divulgado anualmente pela editora Abril.
Desde a implantação, o curso promoveu atualizações e alterações pontuais em sua grade de disciplinas. Em 2009, porém, amadureceu a convicção de que sua estrutura e seu Projeto Político-Pedagógico deveriam passar por uma reforma que aperfeiçoasse a sua qualidade acadêmica, atendesse as demandas geradas pelo advento de novas tecnologias e abrangesse as mudanças significativas ocorridas na indústria e no mercado editorial.

Como iniciativa da Comissão de Coordenação de Cursos do Departamento de Jornalismo e Editoração (CoC-CJE), os trabalhos para a reforma transcorreram ao longo de três anos, com ampla participação do corpo discente, total adesão dos docentes e a colaboração dedicada de funcionários, respaldados pelas orientações técnicas recebidas da Pró-Reitoria de Graduação. 
Foram quatro os principais critérios para a reforma: as diretrizes curriculares do MEG (BRASIL, 2001) para o bacharelado em Comunicação Social, com habilitação em Editoração; o ciclo de produção editorial - do autor ao leitor - em suportes impressos e digitais, com ênfase no livro; as necessidades para uma formação de excelência, com a articulação entre Ensino, Pesquisa e Extensão; o corpo docente disponível e suas especialidades, mas também a falta de professores em alguns setores estratégicos do curso (lacuna que, quando da implantação da reforma, foi provisoriamente preenchida com a colaboração de dois professores aposentados da ECA).

Baseadas na necessidade de articulação desses quatro critérios, inúmeras reuniões de grupos ou de todos os docentes, várias delas com livre participação do corpo discente, redundaram em estudos e propostas que sempre levaram em consideração as críticas e sugestões encaminhadas por alunos e ex-alunos, bem como o pronunciamento de editores convidados a se manifestarem. Para que se tenha uma ideia desse processo, sirvam de exemplo os onze ensaios de grade disciplinar avaliados até que se chegasse à proposta aprovada, em vigor a partir de 2012.

As disciplinas obrigatórias são distribuídas em seis grupos:

1. Formação Geral e Humanística, com dez disciplinas voltadas para a cultura e literatura brasileira, história do livro, ética, filosofia, sociologia e teoria da comunicação;

2. Formação Específica em Edição de TeXTO, com oito disciplinas distribuídas entre língua portuguesa, teorias e práticas da leitura, ecdótica, critérios de seleção de originais literários, livros infantis e juvenis e edição de livros escolares;

3. Formação Específica em Design Gráfi$\mathrm{CO}$, com seis disciplinas que contemplam o domínio teórico e prático fundamental e o conhecimento de arte e de design para a boa atuação do futuro editor: produção gráfica, design editorial, design de interação e tecnologia digital para editoração;
4. Aspectos Legais, Mercadológicos e Metodológicos da Produção EdTtOrial, com seis disciplinas que, recentemente, foram reduzidas a cinco com a fusão de duas delas em uma, sem alteração da carga horária, pois essa soma as das que se fundiram: introdução à editoração, teoria e método de pesquisa em comunicação, políticas públicas de leitura, legislação da indústria editorial e mercado editorial.

5. Disciplinas Laboratoriais, três disciplinas com o objetivo de colocar em prática o conhecimento adquirido em todas as outras, a capacidade de articulação de ideias e a aplicação à atividade de produção editorial: laboratório de produção editorial (I, II e III).

6. Trabalho de Conclusão do Gurso (TCC), constituído de uma disciplina denominada Projeto Experimental em Produção Editorial, que pressupõe a sistematização do conteúdo e das experiências acumuladas durante o período de graduação, quer por meio de trabalho monográfico, no qual o aluno demonstre sua vocação para a pesquisa acadêmica, quer pelo desenvolvimento de um projeto, envolvendo todas as etapas da produção editorial.

A seleção das disciplinas contempla integralmente as diretrizes curriculares do MEG, bem como a necessidade de proporcionar uma formação de excelência aos egressos. A divisão das disciplinas nos seis grupos mencionados tem um aspecto esquemático, mas, na prática, foram ordenadas com o intuito de se criar uma sequência lógica entre elas, que possibilite o aprofundamento do conteúdo ao longo dos semestres. Além disso, elas interagem direta ou indiretamente, sendo que várias se articulam de modo sistemático para a realização de projetos compartilhados, como edições de livros nas várias coleções mantidas pelo curso (Memória Editorial; Editando o Editor; Primeira Impressão; Reserva Literária; Memória Militante) ou como as revistas Artigo Definido, Quadreca e Originais Reprovados. 
Além de estabelecer a nova grade, o Projeto Político-Pedagógico do curso de Editoração da ECA-USP valoriza atividades de pesquisa, bem como de cultura e extensão, atribuindo créditos aos alunos que se dediquem a elas. Assim estimula-se a participação em projetos de iniciação científica e na organização de eventos, como o já tradicional e prestigiado Fórum de Editoração, a Jornada Reserva Literária e lançamentos de obras produzidas no âmbito da Com-Arte, editora-laboratório do curso. Alunos que realizam estágios profissionais em editoras são também contemplados com créditos.

Com a ampla participação discente e docente nas instâncias de estudo, discussão, formulação e aprovação, o Projeto Político-Pedagógico do curso de Editoração da ECA-USP resulta numa experiência democrática bem-sucedida de construção curricular que ratifica, aprimora, atualiza e acentua a natureza múltipla do profissional que se pretende formar, seja na perspectiva da vida acadêmica, seja sob o prisma das exigências do mercado, seja em sua tarefa suprema de formar cidadãos conscientes de seu papel social.

\section{Bibliografia}

BRASIL. Ministério da Educação (MEG). Diretrizes Curriculares Nacionais, 2001. Disponível em: 〈http:// portal.mec.gov.br/cne/arquivos/pdf/CES0492.pdf $>$. Acessado em 25 fev. 2017.

Projeto Político-Pedagógico do Curso de Editoração da ECA-USP. Disponível em: <http://www.usp.br/cje/anexos/ ppp_editoracao_2012.pd†. Acessado em 25 fev. 2017

Publicado em 31/03/2017. 